\title{
A transition to sustainable ocean governance
}

\author{
Tanya Brodie Rudolph ${ }^{1}$, Mary Ruckelshaus ${ }^{2 凶}$, Mark Swilling ${ }^{3}$, \\ Edward H. Allison (1D 4,5, Henrik Österblom (1D ${ }^{6}$, Stefan Gelcich (1D ${ }^{7}$ \& \\ Philile Mbatha ${ }^{8}$
}

Human wellbeing relies on the Biosphere, including natural resources provided by ocean ecosystems. As multiple demands and stressors threaten the ocean, transformative change in ocean governance is required to maintain the contributions of the ocean to people. Here we illustrate how transition theory can be applied to ocean governance. We demonstrate how current economic and social systems can adapt to existing pressures and shift towards ocean stewardship through incorporation of niche innovations within and across economic sectors and stakeholder communities. These novel approaches support an emergent but purposeful transition and suggest a clear path to a thriving and vibrant relationship between humans and the ocean. Oceans provide important natural resources, but the management and governance of the ocean is complex and the ecosystem is suffering as a result. The authors discuss current barriers to sustainable ocean governance and suggest pathways forward.

A new relationship between humanity and the ocean is required to secure the continuity of the diverse life support roles provided by the sea ${ }^{1,2}$. Ocean governance faces the challenge of reflecting the multi-dimensional and interconnected role that the ocean plays in environmental health, economic prosperity and human well-being ${ }^{1-4}$, including justice and equity ${ }^{1,5-7}$.

The ocean, when considered as a whole, cannot be defined solely as either a state-governed public good, nor as a commodity or private good. The World Commission on Environment and Development states that "Oceans are marked by a fundamental unity from which there is no escape. Interconnected cycles of energy, climate, marine living resources, and human activities move through coastal waters, regional seas, and the closed oceans" ${ }^{\prime}$. The increasing prevalence and dominance of transnational corporations is also challenging the central role of governments in governance. Ocean governance thus needs a transformative shift from a state-centric approach to a global approach ${ }^{9}$ that takes into account the embeddedness of the ocean and associated actors in the wider planetary system ${ }^{8,10}$. It is therefore best seen as a commons (see Glossary in Table 1) - a non-state, non-private shared resource that can only be protected if stakeholders who depend on it take collective responsibility for preservation and restoration ${ }^{11}$ with selfdevised protocols, values and norms ${ }^{12}$. An integrated approach will mean a transition to an adaptive, responsive global governance system (defined in Glossary in Table 1) for governing the ocean-as-commons; an approach which "does justice to humanity's obligations to itself, and to

\footnotetext{
${ }^{1}$ Centre for Complex Systems in Transition, University of Stellenbosch, Stellenbosch, South Africa. ${ }^{2}$ The Natural Capital Project, Woods Institute for the Environment, Stanford University, Stanford, CA, USA. ${ }^{3}$ School of Public Leadership, University of Stellenbosch, Stellenbosch, South Africa. ${ }^{4}$ Nippon Foundation Ocean Nexus Program, Earthlab, University of Washington, Seattle, WA, USA. ${ }^{5}$ WorldFish, Penang, Malaysia. ${ }^{6}$ Stockholm Resilience Centre, Stockholm, Sweden. ${ }^{7}$ Center of Applied Ecology and Sustainability, Department of Ecology, Pontificia Universidad Católica de Chile, Santiago, Chile.

${ }^{8}$ Department of Environmental and Geographical Science, University of Cape Town, Cape Town, South Africa. ${ }^{凶}$ email: mary.ruckelshaus@stanford.edu
} 


\section{Table 1 Glossary of terminology.}

Commons

Environmental stewardship

Landscape pressures

Generative ownership

Legal regime

Meta-governance

Niche innovations

Regime (also socio-technical regime)

Reflexive governance

Polycentric governance

Volitional governance
A non-state, non-private shared resource, plus a defined community that devises protocols, norms and values to manage it (eg. Earth's atmosphere) 33,42

Actions taken by individuals, groups, or networks of actors to protect, care for, or responsibly use the environment in pursuit of environmental and/or social outcomes in diverse social and ecological contexts 63 Fundamental system conditions typically exhibiting gradual changes (e.g., demographics, resource depletion, climate change, technological innovation, urbanization, etc.) that synergistically and incrementally lead to shifts in the state of the environment and impacts on valued parts of ecosystems or on society Categories of private ownership which generate beneficial outcomes for common good ${ }^{117}$ A legal framework comprising principles and rules governing human activities or processes (eg. UNCLOS) Governance of governance among interacting groups 69

Novel approaches through which sectors or stakeholder communities interact with or produce goods from a social-ecological system in response to landscape pressures (eg. emergence of local renewable energy systems as an alternative to fossil fuels)

A tightly knit combination of regulations, key operators that produce products or services, consumers who depend on those products/services, the revenues that governments/agencies/regulators extract in the form of levies/taxes etc, the financial institutions who provide debt/equity, plus a substantial infrastructure operated by people who have been trained over decades to understand and operate the system in certain ways (eg. fossil fuel-based energy system) ${ }^{118}$

When the foundations of governance (the concepts, practices and institutions by which societal development is overseen) are questioned, and more relevant and effective alternatives are reinvented to reshape those foundations

A system of decision making in which multiple governing bodies interact to make and enforce rules within a specific policy arena or location

Voluntary commitments aimed to deliver outcome-oriented activities ${ }^{84}$ eg. Nationally Determined Contributions under the Paris Agreement, the Voluntary National Review process set up under the United Nations SDG review mechanism ${ }^{70}$, and voluntary commitments under the Our Ocean Conference series (Registry of Voluntary Commitments UN Our Ocean Conference). the planet which is its' home" (International Court of Justice Judge Weeramantry in Gabickovo-Nagymaros case 1997) ${ }^{13}$.

These global and intertwined dynamics ${ }^{14}$ are not fully reflected in the current legal definition in the United Nations Convention on the Law of the Sea (UNCLOS) and international customary law. The ocean comprises a global commons in Areas Beyond National Jurisdiction of any nation-state's authority (the high seas and the seabed beyond continental shelves; Art 89 UNCLOS) as well as areas within nation-state sovereignty (maritime zones of coastal states including the Territorial Sea Art 2, 3, Exclusive Economic Zone Art 55, and Continental Shelf Art 76 (UNCLOS)). Governance of the Areas Beyond National Jurisdiction is generally weaker than within national jurisdictions ${ }^{15}$. A treaty for Biodiversity Beyond National Jurisdiction is being negotiated under the auspices of the United Nations ${ }^{16}$. Until it is finalised, more than $40 \%$ of the surface of the Earth has limited formal legal protection for its natural habitat and functional ecosystems (except through a patchwork of sectoral organisations) $)^{6,17}$.

The rationale for a sustainable ocean transition is becoming increasingly urgent ${ }^{1,18}$. If we do not act to change course, the ocean's key biophysical functions could collapse ${ }^{1}$. Wider global and regional pressures (what we refer to as landscape pressures'-see Glossary in Table 1) on the ocean include rising levels of greenhouse gas emissions ${ }^{1,19}$, changes in chemistry, which impact species and food webs throughout ocean ecosystems ${ }^{2,8,20}$, warming $^{21-23}$, deoxygenation ${ }^{24}$, overfishing, and run-off of pollution from land and coastal sources ${ }^{1,25}$. The Earth system-and the ocean in particular-is at risk of "irreversible or unimaginable" change 26 .

In addition, the ocean is becoming a new economic frontier for production of energy, minerals and food ${ }^{6}$. Coastal zones are not only at the forefront of transition challenges, but they bear the brunt of climate change impacts ${ }^{27}$. Ocean sustainability transitions are therefore interdependent with those on land. The coastal zone serves as the interface between land-based society and expanded ocean economic activity. Coastal land use planning and integrated ocean management are therefore critical elements of a transition to a sustainable ocean economy ${ }^{28}$.

The ocean has been identified as one of six key coupled social-ecological systems that require transformative change to achieve the UN sustainable development goals ${ }^{29}$. Here we argue that a purposeful transition to a more sustainable ocean system requires a profound departure from business-as-usual to a global regulatory effort to pursue ocean sustainability. Transformation to a thriving ocean system requires changes in governance across sectors and scales, with effective and inclusive participation by multiple actors ${ }^{10,30}$. The end result would be a form of "polycentric governance" (see Glossary in Table 1) that can manage shared resources and ocean space ${ }^{31}$. Ocean polycentricism may require a rule-setting global institution (such as an Ocean Agency, Box 1), to support multiple governing bodies by establishing a shared vision, and creating principled guiding frameworks and processes to facilitate coherent systems-oriented regulation $\left({ }^{10}\right.$. In a complex world characterized by nationalist resistance to multilateralism on the one hand and the unviability of centralized control on the other (eg. ${ }^{32}$ ), such a polycentric system will require a balance between markets, government regulation and peer-topeer commons-type institutional configurations.

Although transitions to what the Preamble to the Sustainable Development Goals (SDGs) referred to as a "transformed world" are being tackled from many different perspectives (see ref. ${ }^{33}$ ), two mainstream schools of thought have emerged. Firstly, there is resilience thinking associated with the international Resilience Alliance and the Stockholm Resilience Centre. Here the focus is on regime shifts and transformations of social-ecological systems to cope with, adapt to, and transform in the face of change ${ }^{30,34-36}$. Secondly, there is the Dutch School of sustainability transition theory that emerged after the turn of the millennium ${ }^{37-39}$. Whereas resilience thinking's roots are in ecosystem science ${ }^{40}$, the 


\section{Box 1 | Meta-governance Institution (e.g., an Ocean Agency)}

Although current agencies and multi-lateral institutions (such as UNEP, FAO, IMO) have validity and legitimacy5,32, progress towards a sustainable ocean is not in step with the pace of climate change and ocean degradations. Oceanic impacts are being experienced acutely among islands, coasts, fisheries and polar seas ${ }^{144}$. What is required is not "merely rearranging the organization of chairs on our planetary Titanic"32. Without fundamental change, the growth of the ocean economy is likely to exacerbate existing inequalities and accelerate the depletion of ocean resources and degradation of planetary environmental systems. Effective ocean polycentrism may therefore require a rule-setting global institution (or the restructuring of an existing global institution) to represent a common world view or value system, and to create good governance-inspired flexible frameworks for the implementation, monitoring and management of blue economy activities 5 . This global institution also would guide national policies and corporate activities, and manage disparate views and ideas of the multiple actors in ocean and coastal governance processes ${ }^{145}$. Governing the trade-offs between different policy objectives which will arise in multi-scalar, polycentric governance models will be easier if meta-governance principles such as transparency, accountability, and inclusivity are in place ${ }^{3,146}$. Without a shared set of norms, values and 'rules of the game', the bottom-up flourishing of commons initiatives will not have the systemic, transformative impact that is required. This meta-governance institution could be supported by a knowledge commons and mandated by states to create principled frameworks (eg. as in the UNESCO Man and Biosphere Program) to address oceanrelated challenges at different scales, in response to changing needs, capacity and context (eg. the FAO Voluntary Guidelines for Securing Small Scale Fisheries).

sustainability transitions approach emerged from evolutionary economics, science/technology and society studies, and innovations research. Both are premised on an interpretation of complexity theory and represent the foundation for the arguments presented here.

\section{The dynamics of sustainable transitions and transformations} Since the beginning of human civilization, people have collaborated to secure and protect natural resources they have depended on for their survival ${ }^{11}$. Communities have routinely devised complex polycentric governance arrangements to transform open-access environments (such as fishing grounds) into regulated commons regimes ${ }^{11,41}$. Commons management of this nature is characterised by a commitment to equitable access, use and sustainability ${ }^{42}$.

During the process of industrialization, the commons has gradually been replaced by either private ownership or public goods owned or controlled by states ${ }^{43,44}$. Recent work to support sustainability transitions or transformative change in governance towards ecosystem stewardship has brought the commons back into focus, with a particular focus on natural systems, including forests, water resources, soils and the ocean ${ }^{45}$. Stewardship has been defined as a strategy to respond to and shape socialecological systems under conditions of uncertainty and change to sustain both people and planet ${ }^{44}$. Stewardship approaches are designed to promote resilience when existing systems (sociotechnical regimes, see Glossary in Table 1) are no longer able to accommodate or adapt to a new set of ecological, social or economic conditions ${ }^{26,37-39,46}$. Socio-technical regimes can reinforce entrenched governance arrangements that prevent effective responses to these landscape pressures. For example, despite the rapid growth in renewables worldwide, there is no significant decline in $\mathrm{CO} 2$ emissions, largely because of inter-dependent sets of interests reinforced by existing tax and subsidy regimes ${ }^{47}$. For a given socio-technical regime to give way to an alternative, a vast array of complex system components need to be dismantled and re-organized. Interests dependent on these socio-technical regimes often resist change. Resistance arises as a result of various factors including entrenched power relations, dominant economic or political subsystems, the limits of human imagination and societal norms ${ }^{30}$, or the failure to recognize that natural systems such as the ocean would not necessarily return to historically familiar conditions ${ }^{48,49}$.

How regimes respond to these pressures will depend on their internal capacity to manage change, and how they access new knowledge about alternatives. Without these conditions, regimes resist change and niche innovations can emerge. Such innovations are alternatives that respond to landscape pressures by challenging the logic and existence of a particular regime (e.g. local renewable energy systems in the face of non-responsive fossil fuel regimes) (see Glossary in Table 1), and which can, under certain conditions, catalyze pathways to transition. The dynamics of systemic change in the ocean economy are depicted in Fig. 1. The model represents the process of isolated, emergent niche innovations, some of which mature (or expand) and ultimately replace unsustainable political, economic and social institutions. This multi-level, dynamic process of transformation is influenced by increasing landscape pressures and informed by shifts in social culture towards a sustainable, commons-centric world view over time. (Conceptually this is similar to the notion of 'seeds of the good anthropocene' ${ }^{50}$ ).

The starting point to define possible transition pathways to ocean stewardship is to (i) detail the primary drivers of change in the system, (ii) showcase demonstrations of how innovative leadership and niche-level experimentation in response to current drivers and incumbent regimes are beginning to shift the dynamics of transition, and (iii) highlight regime responses which have emerged. Although addressing the challenges facing the ocean system will require fundamental transformation, our explicit intention is to explore the evolutionary potential of the present to identify those experiments and change dynamics underway now that may aggregate into a much more significant transformative process in the future.

\section{Transition drivers and responses}

Landscape pressures drive changes in the state of the environment, and impact parts of ecosystems or society. Rising levels of greenhouse gas emissions, and $\mathrm{CO} 2$ levels specifically, represent an overarching threat to a functional ocean ${ }^{1,19}$. Acidification is harming individual species and food webs, especially in the subarctic Pacific and western Arctic Ocean ${ }^{2,20,51}$. The ocean has absorbed over $90 \%$ of the excess heat from global warming, with consequences for the biogeography of species adapted to specific temperature ranges ${ }^{21-23}$. Declining oxygen content dramatically manifests in increases in extreme hypoxic events and species dieoffs $^{24}$, disrupting nearshore ecosystems and their dependent communities. Other primary landscape pressures on ocean systems include habitat destruction, overfishing, and run-off of pollution from land and coastal sources ${ }^{1,25}$ (Fig. 1).

In a reinforcing feedback loop, climate change and development pressures lead to changes in the ocean state (e.g., frequency of extreme storm events, food web structure), thereby increasing 


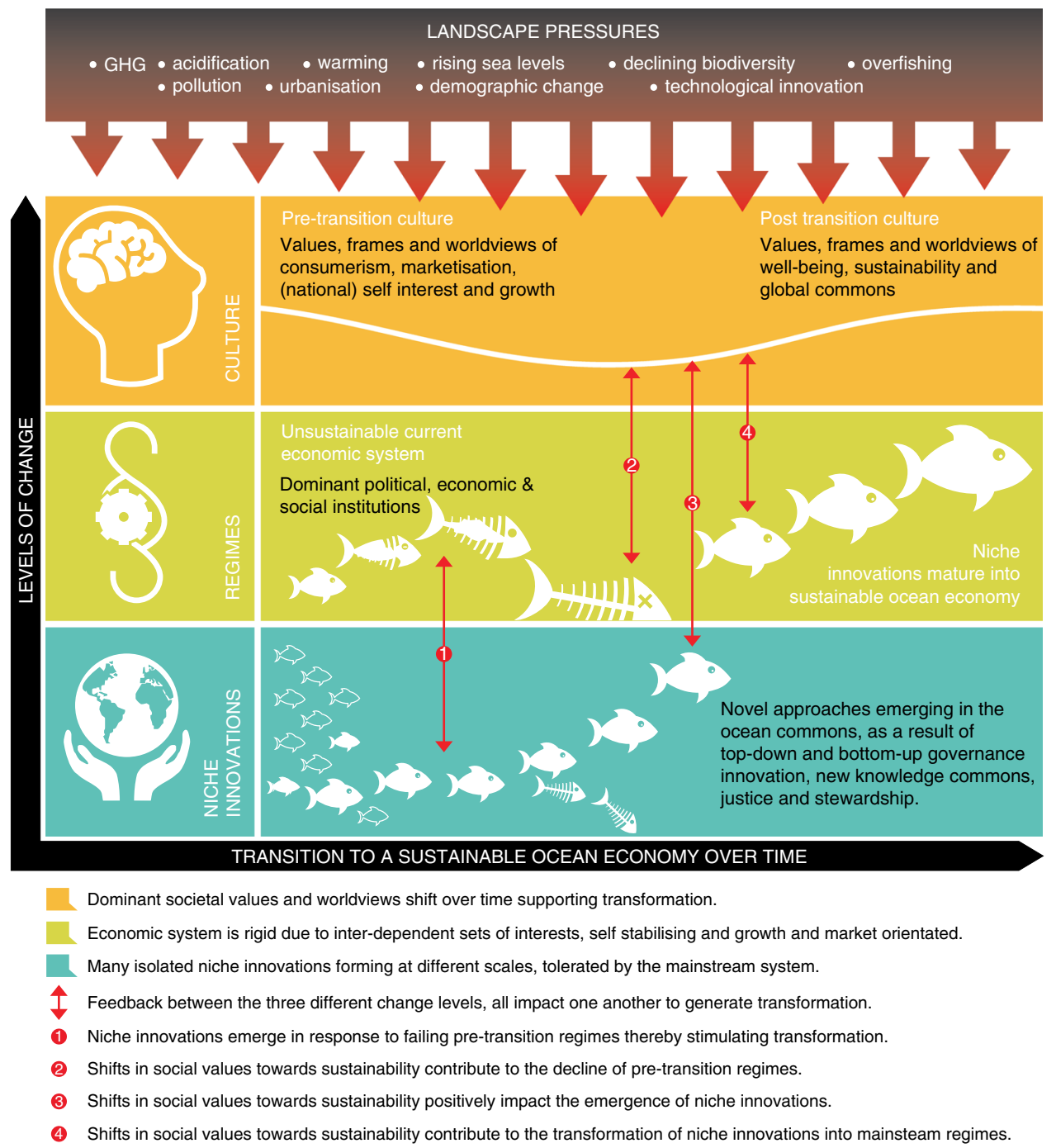

Fig. 1 Dynamics of system-level change in the ocean economy. The elements of the ocean social-economic system undergoing systemic change as a result of interactions between culture, existing regimes, and niche innovations, all of which are influenced by landscape pressures. Redrawn from Narberhaus and Sheppard ${ }^{116}$, with permission from the author and in compliance with the CC BY-SA 3.0 license, 2015 https://creativecommons.org/ licenses/by-nc-sa/3.0/.

vulnerabilities and undermining key economic activities, such as fisheries and aquaculture, tourism and shipping ${ }^{2}$. Transitions to a more sustainable ocean may occur when current socio-political regimes confront landscape pressures they were not designed to handle. Responses by specific sectors or communities may generate innovations that, when combined and scaled, can contribute to enabling these transitions.

These niche innovations can be technical, cultural, social, economic, political or legal in nature-or a mixture of all-and provide examples of what is possible, thus catalysing further transition dynamics (Fig. 1). Several regime responses illustrate how shifts in existing ocean systems towards sustainability can be made possible. For example, the International Maritime Organization and the shipping industry have contributed to significant regime responses in the shipping sector, demonstrated by the regulation of green ship recycling ${ }^{52-56}$ and the decarbonisation of ocean transport ${ }^{57}$. In addition, fisheries certification schemes such as that developed and overseen by the Marine Stewardship Council have contributed to transparency, accountability and traceability in the ocean based food extraction regime ${ }^{58}$, but have also generated increased attention to what this certification scheme does not do, namely address social injustices arising from competitive but declining fisheries ${ }^{59,60}$. Finally, the agreement being negotiated under the provisions of UNCLOS, known as the internationally legally binding instrument for conservation and sustainable use of Biological Diversity in Areas Beyond National Jurisdiction, is intended to address challenges in marine biotechnology such as benefit sharing, area-based management tools, environmental impact assessments, capacity-building; and the transfer of marine technology ${ }^{61}$. We focus below on innovations that have emerged as responses to landscape pressures, in order to further demonstrate such transition dynamics.

Increased attention to ocean challenges and opportunities is generating a diversity of niche innovations in the ocean system. These innovations are distinctive in that they entail forms of stakeholder collaboration and co-development of solutions that are driven by an overriding concern to protect and regenerate the ocean commons. Niche innovations emerge beyond-but interact with - the regimes within which they occur, and they can eventually coalesce into alternative regimes (Table 2, Fig. 1, and Boxes 2-4). Existing regimes can engage with and absorb niche innovations as their way of responding and adapting to the 


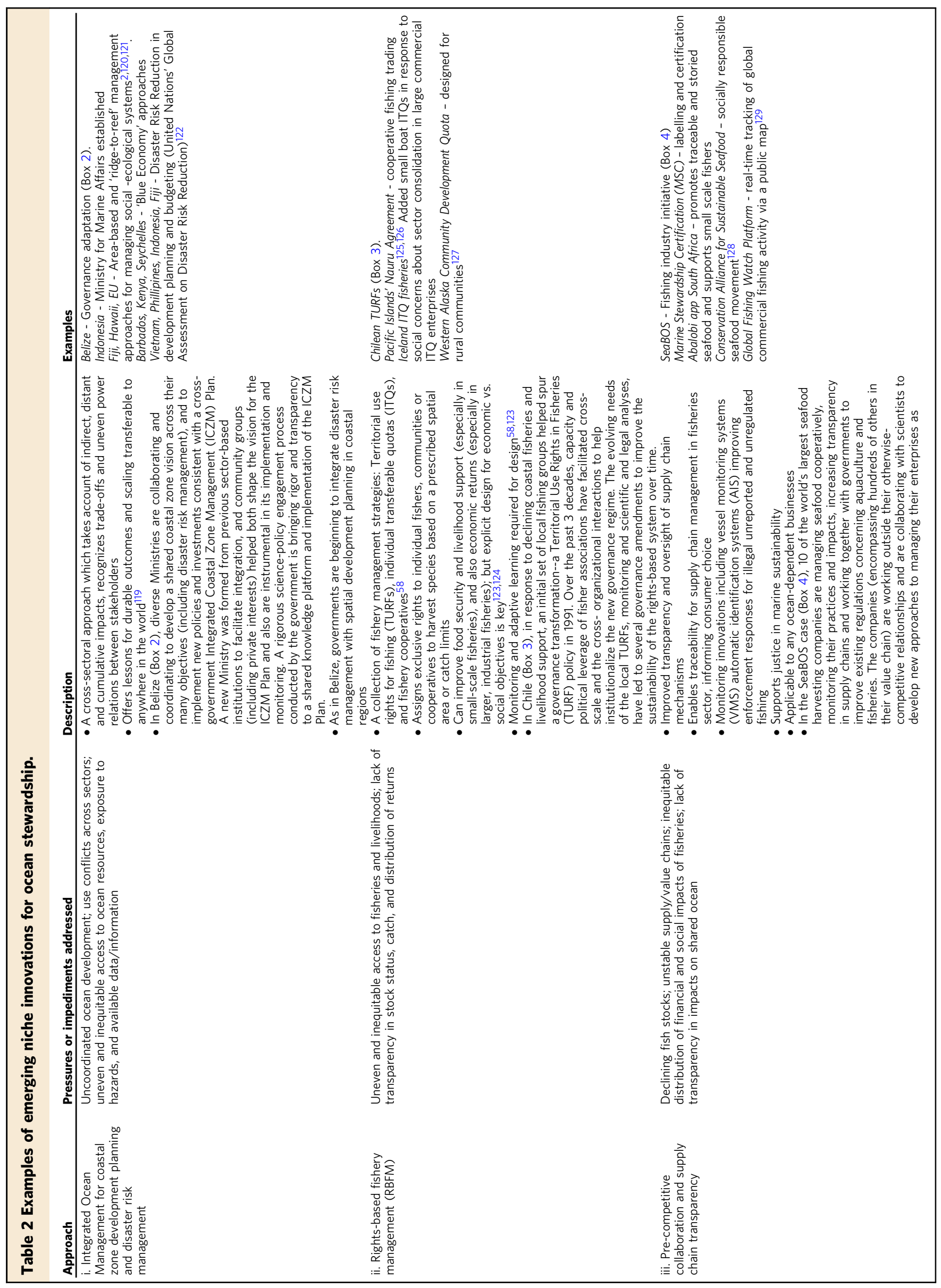




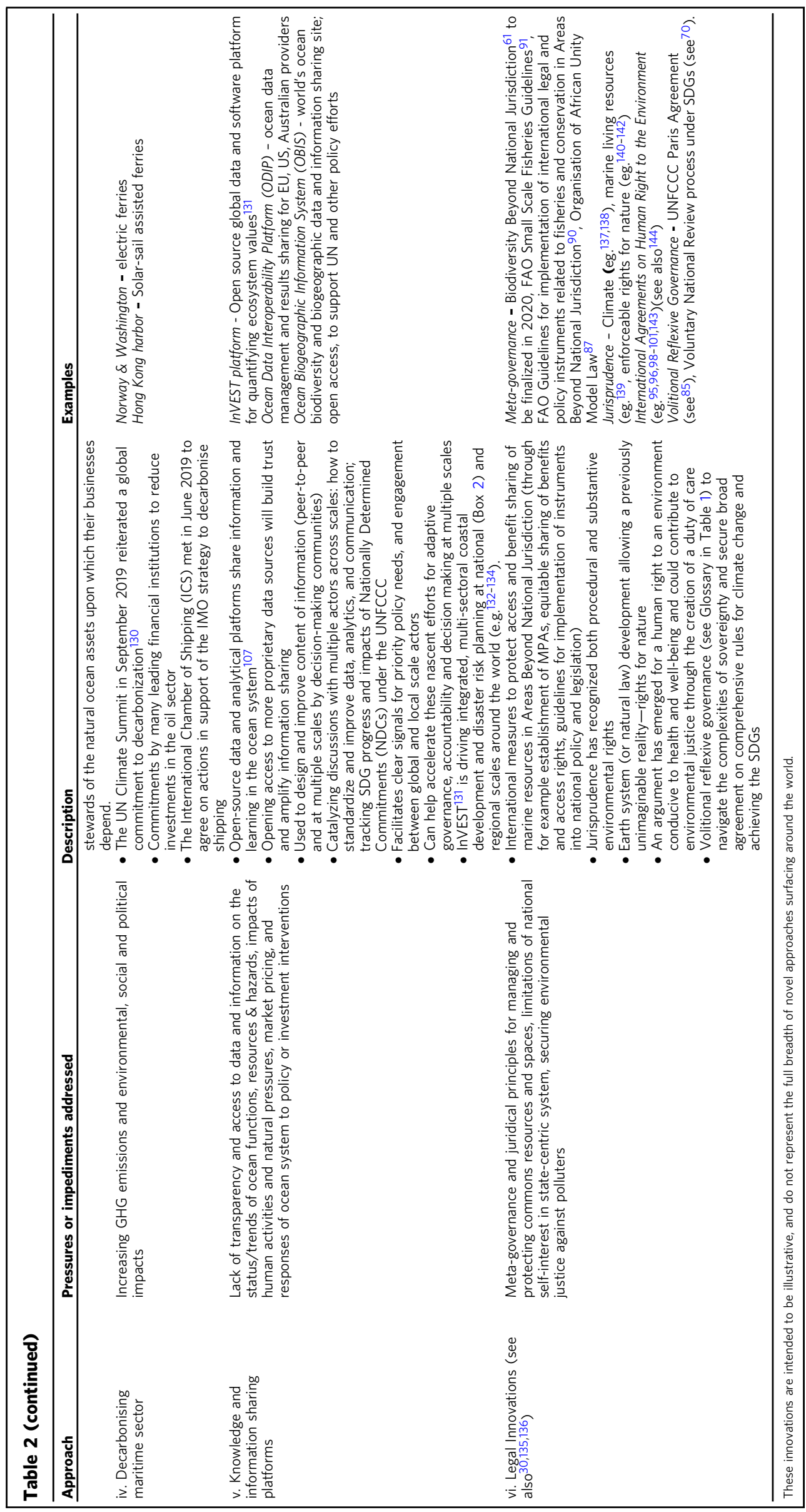




\section{Box 2 | Coastal zone development planning in Belize}

The government of Belize's Coastal Zone Act of 2000 recognizes the value of multi-sectoral, integrated spatial planning to guide policy and investment for more sustainable use of the coastal zone. The government approved a National Integrated Coastal Zone Management Plan (ICZMP) in 2016, led by a new Ministry inspired by the integrated development planning, connecting in one department Agriculture, Fisheries, Forestry, the Environment and Sustainable Development ${ }^{147}$. The plan was co-developed through an interactive stakeholder engagement process, beginning with identifying shared objectives for artisanal and commercial lobster and conch fisheries, reducing risk from sea-level rise and storms, and sustainable tourism benefits, the largest sector of the Belizean economy ${ }^{148}$. The final Plan is projected to achieve these goals through improved protection for mangroves, coral reefs, and seagrass beds $133,147,148$.

The final ICZMP highlights the importance of coordinating management of, and investment in, a diverse set of activities and actors, ranging from those affecting coastal pollution, dredging, fisheries, aquaculture, and tourism development, to education, social resilience to climate change, and preservation of cultural heritage. The plan led the Belizean government to enact a permanent ban for all oil exploitation within the second largest coral reef in the world. The ICZMP actions and new zoning-based management are being implemented with funding from the government, the Inter-American Development Bank, and other sources. The Belize Plan has been hailed by UNESCO as "one of the most forward-thinking ocean management plans in the world"149, and in 2017, UNESCO removed the Belize barrier reef from the World Heritage List in Danger because of the protections provided in the government ICZMP.

The key innovations in the Belize ICZMP process include a legal government mandate requiring a cross-sectoral spatial planning process. Such laws in and of themselves do not necessarily lead to transformation of ocean management. Belize's Integrated Coastal Zone Management Authority and Institute (CZMAI) played a key role in designing the co-development process for the ICZMP, and continues to lead its ongoing implementation and adaptation. The science-policy process also included training of Belizeans on the scientific and policy aspects of Integrated Ocean Management, increasing the chances that the process will be internalized in government and civil society activities ${ }^{148}$.

\section{Box 3 | Chilean territorial use rights fisheries}

After an overfishing crisis led to critical closures of the Chilean abalone ("Loco") fishery in the late 1980s, Chile enacted the first step in a governance transformation-a Territorial Use Rights in Fisheries (TURF) policy in 199150. As of 2013, there are over 450 TURFs in full operation, making up $>1100$ $\mathrm{km}^{2}$ of subtidal habitat decreed to fisher organizations in Chile ${ }^{153}$. This network has been established by numerous associations of fishers under one policy instrument, Chile's National Fisheries and Aquaculture Law 151,152. As a result of the TURFs, Chile's artisanal sector has increased in importance, with landings consistently surpassing the industrial catch since 2008. Artisanal fisheries are a significant source of employment for coastal communities, and their harvests represent a key source of nutritional food for many rural communities. Increases in biomass and size of individuals from species within properly managed TURFs also are demonstrating the potential of this rights-based management approach to sustain ecosystems and fishery benefits 151 .

The national enabling legislation, combined with the presence of scientific knowledge, and the capacity and political leverage of fisher associations who facilitated the cross- organizational interactions for change, each were key in institutionalizing the new governance regime. Participation in the program is voluntary, a key component of adaptive governance for a more resilient system. The TURF network has improved the knowledge of fishers and their access to learning and motivation for stewardship, especially as it relates to harvest management practices, biological aspects of the resource, and the interactions of the target species with other elements of the ecosystem.

While the 25-year old Chilean TURF model has proven its potential to improve the sustainability of fisher communities and fisheries, its governance must continue to evolve as information on social and ecological barriers to further scaling emerges ${ }^{150}$. TURFs convey rights to fishers and allow them a collective voice in the long-term management of the resource, a key component of their adaptability and responsiveness to changing social-ecological conditions. Currently, there is room for improvement with respect to enforcement, profitability, socioeconomic impacts on resource users, and the adaptability of the policy to local realities. Science is key to informing ways to maintain the policy, enable adaptation of TURFs and identify new conditions that must be improved for building resilience of TURFs or enable further transformations.

perceived or real pressures. Sometimes these niches are too weak and are unable to generate alternative regimes, resulting in landscape breakdown and return to previous regimes ${ }^{62}$. In the right conditions, where the regime is accommodating, and the innovation is strong enough, a transition becomes possible (Fig. 1). To illustrate the breadth of niche innovations unfolding in the ocean system, we highlight six examples of how stakeholder communities are galvanizing around new approaches for ocean stewardship (Table 2). These are: (i) Integrated Ocean Management for development planning and disaster risk management through coastal zone planning (also see Box 2); (ii) rights-based fishery management in Chilean fisheries; (also see Box 3); (iii) pre-competitive collaboration and supply chain transparency in the seafood industry (also see Box 4); (iv) decarbonizing the maritime sector; (v) information sharing platforms for cogeneration of knowledge and learning, and (vi) emerging legal approaches to the ocean commons.

Despite these innovative responses, and emergent niches, key challenges in shifting dynamics to sustainable ocean governance remain, including a lack of coherence, coordination and clarity ${ }^{27}$, outdated regulatory assumptions ${ }^{30,49}$, conflict over allocation of space and rights of access to resources ${ }^{63}$, inadequate monitoring and enforcement (eg. ref. ${ }^{9}$ ), lack of inclusivity (eg. ref. ${ }^{32}$ ) and inequity in the distribution of ecosystem service benefits (eg. ref. ${ }^{5,64}$ ). A purposeful shift towards governance for a sustainable ocean is required to address these challenges and allow the innovative approaches to emerge more fully.

\section{Pathways for transition to a sustainable ocean economy}

Conventional theories of change assume that political, social or market interventions can shift a system from one structure to another (such as the transition from feudalism to capitalism) ${ }^{65}$. These theories of change do not always apply for complex systems such as the ocean, where more incremental, learningfocused, and pragmatic approaches are more likely to lead to fundamental transformation ${ }^{66}$. Such transitions through incremental change depend on active learning based on real-time information. This is not necessarily a less radical option ${ }^{65}$. 


\section{Box 4 | Seafood business for ocean stewardship}

The Seafood Business for Ocean Stewardship (SeaBOS) initiative is an innovative collaboration among 10 of the largest global seafood companies that is transforming business operations for wild capture fisheries and aquaculture production. Collectively, this small group of 10 companies influences the strategic direction of more than 639 subsidiaries along the seafood value chain, with operations in at least 93 different countries, and participation in fisheries and aquaculture decision making institutions such as RFMOs. Under the SeaBOS platform, the world's leading seafood businesses are managing seafood cooperatively, monitoring their practices and impacts, and charting a new path for their sector. They have pledged to address Illegal, Unreported and Unregulated (IUU) fishing; work towards full traceability and transparency throughout their supply chains; make efficient use of aquaculture feeds and fish feed resources from sustainably harvested stocks; apply existing certification standards; eradicate labour abuses and human rights violations from their supply chains; reduce the use of plastics in seafood operations; work towards reducing the use of antibiotics in aquaculture; and prevent harmful discharges and habitat destruction. The participating businesses also have pledged to work together with governments to improve existing regulations concerning aquaculture and fisheries ${ }^{154}$. The scope of the undertaking spans every continent and in all segments of seafood production. The collaborative nature of the SeaBOS project also helps companies share information to develop best practices which in turn, has helped to build trust and common purpose. An on-deck species-detecting camera and facial-image recognition software pilot is aimed at identifying illegal catch and undocumented fishermen on board vessels. SeaBOS has recognized the crucial role of scientists in framing the urgency of problems and potential solutions. The initiative is an on-going experiment that is being closely monitored to understand the significance of the changes over time. Such initiatives engaging with the private sector are best considered a complementary approach to existing processes, such as government regulations. This initiative is improving the prospects for transformative change by providing novel links between science and business, between wild-capture fisheries and aquaculture industries, and across geographical space ${ }^{154}$. SeaBOS is best described as a co-production initiative between science and business, in which companies can develop their agency ${ }^{74}$ to influence change, thereby contributing to amplifying new norms of ocean stewardship.

The governance mechanisms for managing both adaptive and transformative change require radical shifts if a more responsive global ocean governance system is to be established $10,30,67,68$. Reconfigured nation-state authority ${ }^{69}$ would occur by introducing principles such as reflexive, iterative governance (for example the voluntary national review process established for implementation and review of the UN Agenda 2020 ${ }^{70}$ ) (Glossary in Table 1), by including polycentric modes of governance (nested scales of governance from local to national or global scales, demonstrated by the Belize and Chilean examples, Table 2, Boxes 2 and 3), and by creating meta-governance frameworks (such as the regime in Antarctica (Antarctic Treaty System ${ }^{71}$ ). Empowered communities participate in decisions through legal rights as well as shared knowledge and information (Table 2). Finally, stewardship responsibilities should be integrated with user and property rights, and mainstreamed among corporations (evident in the SeaBOS example in Box 4). The elements of a transition to global ocean governance are depicted in Fig. 2, and elaborated below.

A transformation to ocean stewardship is not a clear-cut, onestep change. Rather it is messy, fraught, contested, and occurs across different scales and domains ${ }^{33,72}$. Nevertheless, as we have shown, there are notable experiments and change dynamics already underway. The scale and scope of the contemporary transition required now is similar to that of the transition from hunter-gatherers to agrarian societies, and from agrarian societies to industrial societies ${ }^{33,73}$. In order to navigate the myriad complexities of this ocean transition, a balancing of economic, social and environmental objectives is required ${ }^{5,10}$. For example, the transformative approach of the United Nations' 2030 Agenda and the Sustainable Development Goals (SDGs; specifically SDG 14life below water) weaves together the numerous strands of sustainable development into an integrated set of ambitious goals that provides "coherence between policies and sectors, in all contexts-local, regional, national, transnational and global" 26 . It also provides a fundamental impulse for humanity-a common goal or a new "moon shot" for the global community ${ }^{26}$. The consistent and abiding reference point for the implementation of change is the protection of the commons. Stewardship of the commons has been repeatedly proven to work for millennia, while more recent Westphalian states and neoliberalism have arguably coincided with the age of unsustainability or the "early Anthropocene"10. To protect the commons, a reconfiguration of governance is required.

\section{Reconfiguring governance}

Governance to meet the needs of bottom-up and top-down ocean stewardship processes will be most effective if it draws from three key frameworks: (1) polycentric, or network, governance; (2) voluntary, adaptive governance, and (3) meta-governance.

First, while there is a need to establish common legal principles, the diversity of the ocean commons also requires a system of flexible, adaptive governance to accommodate the interplay of actors with diverging interests ${ }^{10,74}$, involving diverse institutions, overarching rules, mutual adjustment, local action and trust building 30,75,76. "Polycentric", or network governance can create a decentralized system of multiple self- governing and interacting groups at different scales across policy levels ${ }^{45,69,77}$, which often can handle complexity more effectively than centralized, top-down governance ${ }^{78}$. Transformation cannot rely entirely on bottom-up local initiatives-these will not necessarily "add up" to a coherent mode of ocean governance. However, successful selfgovernance of common pool resources by local communities studied by Ostrom ${ }^{11}$ demonstrates the viability of sustainable polycentric governance of natural resources beyond states and markets $3,78-81$ that function to recognise and design policy informed by site-specific preferences, competencies and the constraints of different actors ${ }^{45}$. This local tuning translates into reflexive and transformative governance, and can reconfigure the traditional socio-technical structures of nation-state authority so that they are more responsive to system changes.

Coordinated policy-making across borders and sectors is needed to implement shared goals for the ocean ${ }^{5}$. For example, the integrated planning in Belize (Box 2) allowed for interactions among public and private sector decision makers at multiple scales (local communities to government Ministers to the President). This resulted in distinct goals, policies, and actions for each of the nine different planning regions, that cumulatively created a consistent, shared national vision. Deeply engaged communities at the local level and an adaptive national government gave rise to a reconfigured, more integrated government ministry for improved coordination, and local leaders were empowered to nimbly adjust management of their natural resources to meet environmental, social and economic goals they had defined.

Critically, multi-scalar governance of natural resources can also focus attention on the way marginalized and vulnerable social groups already use, benefit and derive well-being from these resources $^{82}$. For example, the declaration of a UNESCO World 


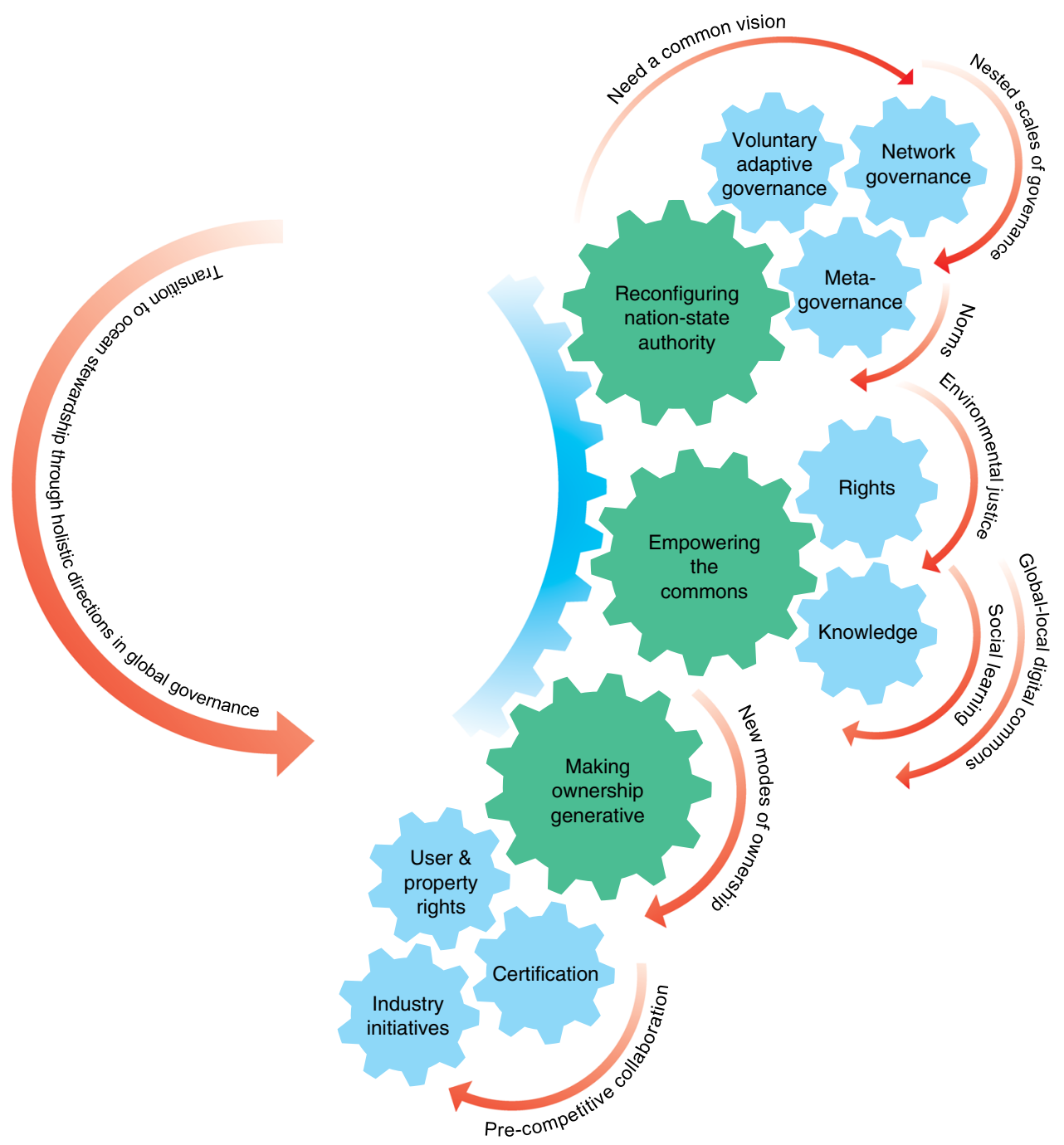

Fig. 2 Elements of a governance transition to ocean stewardship. Elements informing a transition to a more adaptive and responsive global ocean governance system for ocean stewardship driven by three primary levers: reconfiguring nation state governance; empowering the commons through justice, equity and knowledge; and making ownership generative by integrating rights with responsibilities. Concepts based on Bollier ${ }^{12}$.

Heritage Site in Simangaliso in South Africa has disenfranchised a local community from a centuries old heritage of traditional fisheries usage rights, spiritual practices and customs as a result of the lack of authentic engagement with the local community ${ }^{83}$.

Second, voluntary commitments have become a wellrecognized mechanism in international sustainability policy ${ }^{84}$. For example, the UNFCCC Paris Agreement includes voluntary commitments with sufficient flexibility to adapt to unfolding knowledge and system states and adjust to more ambitious goals, as well as obligatory procedural commitments such as transparency reporting 85 . Other examples of this style of "voluntary adaptive governance" include the Voluntary National Review process under the UN SDGs, and the Voluntary Commitments under the United Nations Our Ocean Conferences. In an evaluation of verifiable outcomes of voluntary commitments made at the Our Ocean Conferences from 2014 to 2017, Grorud-Colvert ${ }^{86}$ found that one third of the announcements focused on marine protected areas, and that almost half of these promised actions were completed at the time of publication. These voluntary commitments cumulatively added up to over 5 million $\mathrm{km}^{2}$ of protected area, encompassing $1.4 \%$ of the ocean, almost doubling the quantity of implemented marine protected areas worldwide $^{86}$.
Finally, to complement a flexible, polycentric approach to ocean governance, implementation in practice will need to be aligned with a measure of centralised "meta-governance" to collate information, design, and craft commons regulatory guidelines (Box 1). This central body would be responsible for developing best practices and establishing international guidelines for the implementation, monitoring and management of blue economy activities $^{5}$. Several examples of supra-national frameworks exist in international environmental law. A regional example is the model law drafted by the Organisation for African Unity ${ }^{87}$, which provides a legislative guideline for domestic incorporation of the Convention on Biodiversity ${ }^{88}$, and the Nagoya Protocol ${ }^{89}$. Some established but innovative modes of supra-national governance for the ocean commons have been highly stable, such as the Antarctic Treaty System. The FAO Step-wise Guide for the implementation of international legal and policy instruments related to fisheries and conservation in areas beyond national jurisdiction $^{90}$ is another example of this type of meta-governance instrument. The FAO guide offers a framework for incorporating international instruments pertaining to deep-sea fisheries and biodiversity conservation in the high seas into national policy and law. The guidance includes voluntary, flexible and practical guidelines for domestic legal integration, as well as overarching 
policy and normative guidelines. Other examples include numerous International Maritime Organisation Guidelines, the FAO Small Scale Fisheries Guidelines ${ }^{91}$, the Commonwealth Blue Charter, the European Commission's Blue Growth Strategy and UNESCO's Man and Biosphere framework. The latter, in particular, is a global governance framework whereby global 'rules of the game' for governance of a commons (biosphere reserves) are interpreted and implemented via local governance arrangements $^{92}$.

\section{Empowering the commons through environmental justice and a shared knowledge commons}

In order to ensure fairness and justice, compliance with environmental obligations is a matter of growing concern ${ }^{3,77}$. Stronger accountability, transparency and participation mechanisms will be required to clear conflicts and enable equitable sharing between different ocean users ${ }^{93}$. Compliance with environmental obligations is generally resolved at an inter-state level ${ }^{94}$, but if one accepts that the ocean is a global commons and is part of the global social-ecological system ${ }^{1}$, then in legal terminology, the obligations inherent in concepts such as the sustainable use of natural resources, inter-generational equity and the common concern of humankind fall into the category of obligations owed to the international community as a whole ${ }^{94}$. While commons have traditionally been held in trust by sovereign nations, or collaboratively managed through inter-state relationships, this has proven insufficient to protect the ocean and other planetary commons ${ }^{10,81}$

The international recognition of an environmental human right through an international agreement ${ }^{95-101}$ discussed above would create an opportunity to generate a shift in the collective understanding of legal norms and environmental rights in a similar fashion to that which occurred in the human rights body of law as a result of the Universal Declaration of Human Rights six decades ago. This could initiate a paradigm shift in global culture towards a "human rights-based holistic environmental stewardship for the planet". The FAO voluntary guidelines on natural resource tenure ${ }^{102}$ and on supporting small-scale fisheries $^{91}$ are grounded in human rights principles, and are the first examples of such an approach being applied in fisheries policy. In addition to the embedded normative aspects of equity and justice, we argue that a human right to the environment would form a baseline "net" for governance of the ocean commons, through the inherent potential that such a right provides to address and redress the inequities suffered by individuals and communities exposed to environmental degradation and the unsustainable extraction of natural resources ${ }^{103-105}$.

A shared "information and learning commons" also will be a key feature supporting bottom-up governance processes. The internet has resulted in an entirely new global economy based on many-to-many interactions and vast data flows, fueling the rapid expansion of an information and knowledge commons. Information and communication technologies offer unprecedented potential for improving stewardship of ocean resources and ensuring resilient and productive ecosystems ${ }^{106,107}$. Yet existing databases are not readily accessible, and the compilation of data from ocean mapping, new marine and remote sensors and local knowledge is limited ${ }^{106}$. However, international efforts to address this are underway, such as the Ocean Infohub being developed under the auspices of the Intergovernmental Oceanographic Commission ${ }^{106}$. Such capability could be harnessed to reinforce a bottom-up ocean knowledge commons, enabling effective responses to climate- and development-related changes in the ocean $^{1,2}$. Digitalisation hardly featured in the Paris Agreement or UN Agenda 2030, but it is increasingly clear that digital changes are becoming a key driving force in societal transformation, including for the ocean ${ }^{108-111}$. A shared information and knowledge commons would make "it possible to scale projects through new coordination mechanisms, which can allow small group dynamics to apply at the global scale. It is, thus, possible to combine 'flatter' structures and still operate efficiently on a planetary scale. This has never been the case before" 43 .

In this way. a digital ocean knowledge commons can evolve into the beating heart of a learning system which feeds back into and reinforces reflexive polycentric governance. Initially this would emerge from collaborations between existing research institutions who share a commitment to an open source knowledge commons. Calls for such a knowledge sharing function are emerging for ocean sectors (e.g. refs. 106,107,112), and an integrated information system would go a long way towards improved governance of the commons. Indeed, without this, there is no operating system to create a learning pattern into the future.

\section{Pre-competitive collaboration and property rights}

The final building block of transformed governance to facilitate ocean stewardship is to make ownership generative (see Glossary in Table 1) by ensuring that market mechanisms, pre-competitive collaboration, property and usage rights are aligned with sustainability ${ }^{113}$. The concept of mobilizing corporations or integrating property rights with stewardship, embedded in this transition pathway, is already evident in the ocean economy. ${ }^{63}$. A substantial number of ocean industries have recently engaged in a process to advance pre-competitive collaboration for ocean stewardship, based on science, within the auspices of the United Nations Global Compact ${ }^{106}$. Although this initiative is still very new, it represents an important niche innovation with substantial potential for influencing the governance regime. Such precompetitive collaboration between business actors and science is further illustrated by the SeaBOS example (Table 2 and Box 4). This initiative is based on a vision that a transition is possible. Participating companies share a definition of ocean stewardship as an adaptive and learning based, collaborative process of responsibility and ethics, aimed to shepherd and safeguard the resilience and sustainability of ocean ecosystems for human wellbeing. Fisheries management, in general, has seen a growing emphasis on the role, rights and responsibilities of small-scale fishers in stewardship of local resources ${ }^{63}$. Property rights are currently being integrated with stewardship around the world, as exemplified the Chilean TURF example described in Table 2 and Box 3.

\section{Conclusion: navigating the transition ahead}

The ocean is a global commons. This statement now has very specific implications. The ocean, like the Earth's atmosphere and soils, has made human civilization and life on Earth as we know it possible. However, like the atmosphere and soils, the ocean also faces fundamental threats that could lead to the collapse of critical biophysical functions and major societal disruption. A new system of global governance is required that responds to these pressures and recognizes the ocean as a global commons. Traditional nation-state and market-oriented governance mechanisms are not sufficient. Instead, we could build on a long tradition of polycentric governance arrangements for managing the commons that human civilizations developed long before the modern era of nation-states and markets. What is needed is a new mode of polycentric governance of the ocean-as-commons. This, however, cannot be imposed from above. It needs to build on the transition dynamics already underway at the niche and regime levels. It also must recognize the inherent complexity of the 
social-ecological ocean system, and facilitate nimble, rapid transformation through shared information and joint knowledge development.

A wide range of niche and regime responses have already arisen in response to the existence of landscape pressures, illustrating that a transition of some sort is already underway in the ocean. A purposeful transition would build on what is already emerging, and draw on a shared vision of ocean stewardship, incorporating a wide range of knowledge inputs, and accompanied by institutional capacity at all scales. This requires polycentric governance, transparency, legitimacy, and accountability, a well-resourced digital commons that connects shared data and learning with local innovations and applications; an environmental right to facilitate environmental justice for the ocean, and integration of stewardship responsibilities with rights to commons resources and spaces.

The current ocean governance system is insufficient for handling the challenges facing the ocean ${ }^{10,114,115}$, but there are options. We propose complementary mechanisms that would support and empower change. Further research is required to refine the alternatives, understand the complexities of niche- and regime-level innovations, and understand how promising examples can emerge and amplify the transition. History has demonstrated that social, economic and technological systems can and do transform, and that transitions can accelerate and generate impressive dynamics ${ }^{115}$. A reconfiguration of ocean governance should support a healthy and thriving relationship between humans and the ocean.

Received: 21 December 2019; Accepted: 30 June 2020;

Published online: 17 July 2020

\section{References}

1. IPCC. Summary for Policy Makers. in Special Report on the Ocean and Cryoshphere (eds Pörtner, H. O. et al.) (IPCC, 2019).

2. IPBES. Summary for policymakers of the global assessment report on biodiversity and ecosystem services of the Intergovernmental Science-Policy Platform on Biodiversity and Ecosystem Services. in IPBES eds (Díaz, S. et al.) (IPBES Secretariat, 2019).

3. TWI2050. Transformations to achieve the Sustainable Development Goals. in The World in 2050. (International Institute for Applied Systems Analysis, 2018).

4. OECD. The Ocean Economy in 2030 (OECD, 2016).

5. Bennett, N. J. et al. Towards a sustainable and equitable blue economy. Nat. Sustain. 2, 991-993 (2019).

6. Jouffray, J. B., Blasiak, R., Norström, A. V., Österblom, H. \& Nyström, M. The blue acceleration: the trajectory of human expansion into the ocean. One Earth 2, 43-54 (2020).

7. Cohen, P. et al. Securing a just space for small-scale fisheries in the blue economy. Front. Mar. Sci. 6, 171 (2019).

8. WECD. Report of the World Commission on Environment and Development: Our Common Future (Oxford University Press, 1987).

9. Werle, D., et al. Looking Ahead: Ocean Governance Challenges in the TwentyFirst Century. in The Future of Ocean Governance and Capacity Development (ed International Ocean Institute), 533-542 (Brill Nijhoff, 2019).

10. Kotzé, L. J. Earth system law for the anthropocene. Sustainability 11, 6796 (2019). Article investigates the possibility of articulating a new legal paradigm (Earth system law) for the Anthropocene, and its socio-ecological crisis, including considerations of inclusivity, interdependencies and complexity.

11. Ostrom, E. Governing the Commons: The Evolution of Institutions for Collective Action (Cambridge University Press, 1990).

12. Bollier, D. Transnational Republics of Commoning 2: New Forms of Networkbased Governance. P2P Foundation https://blog.p2pfoundation.net/ transnational-republics-of-commoning-2-new-forms-of-network-basedgovernance/2016/09/16 (2019). Polycentric governance of the commons can introduce new modes of stewardship of natural resources through reconfiguring governance, empowering communities and integrating property rights with stewardship responsibilities.

13. Gabčíkovo-Nagymaros Project (Hungary v. Slovakia). (ICJ, 1997).
14. Österblom, H., Crona, B., Folke, C., Nyström, M. \& Troell, M. Marine ecosystem science on an intertwined planet. Ecosystems 20, 54-61 (2017).

15. Tanaka, Y. The International Law of the Sea, 3rd edn. (Cambridge University Press, 2019).

16. UN General Assembly. International legally binidng instrument under the United Nations Concention on the Law of the Sea on the conservation and sustainable use of marine biological diversity of areas beyond national jurisdiction. A/RES/72/249 (United Nations, 2018).

17. Young, $M$. Then and now: reappraising freedom of the seas in modern law of the sea. Ocean Dev. Int. Law 47, 165-185 (2016).

18. Steffen, W. et al. Trajectories of the earth system in the anthropocene. Proc. Natl Acad. Sci. USA 115, 8252-8259 (2018).

19. Rogers, A. D. \& Laffoley, D. Introduction to the special issue: the global state of the ocean; interactions between stresses, impacts and some potential solutions. Synthesis papers from the International Programme on the State of the Ocean 2011 and 2012 workshops. Mar. Pollut. Bull. 74, 491 (2013).

20. Suggett, D. J. et al. Sea anemones may thrive in a high $\mathrm{CO}_{2}$ world. Glob. Change Biol. 18, 3015-3025 (2012).

21. Cheung, W. et al. Large-scale redistribution of maximum fisheries catch potential in the global ocean under climate change. Glob. Change Biol. 16, 24-35 (2010).

22. Pecl, G. T. et al. Biodiversity redistribution under climate change: Impacts on ecosystems and human well-being. Science 355, eaai9214 (2017).

23. IPCC. Climate Change 2013: The physical science basis. In Contribution of Working Group I to the Fifth Assessment Rreport of the Intergovernmental Panel on Climate Change (ed. Stocker, T. F. et al.) (IPCC, 2013).

24. Stramma, L., Schmidtko, S., Levin, L. A. \& Johnson, G. C. Ocean oxygen minima expansions and their biological impacts. Deep Sea Res. Part I: Oceanogr. Res. Pap. 57, 587-595 (2010).

25. Bailey, R. M. \& van der Grient, J. M. A. OSIRIS: a model for integrating the effects of multiple stressors on marine ecosystems. J. Theor. Biol. 493, 110211 (2020).

26. Independent Group of Scientists appointed by the UN Secretary-General. Global Sustainable Development Report 2019: The Future is Now - Science for Achieving Sustainable Development. (United Nations, 2019).

27. O'Hagan, A. M., Paterson, S. \& Le Tissier, M. Addressing the tangled web of governance mechanisms for land-sea interactions: assessing implementation challenges across scales. Mar. Policy 112, 103715 (2020).

28. Winther, J.-G., et al. Integrated Ocean Management. (World Resources Institute, 2020).

29. Sachs, J. D. et al. Six transformations to achieve the sustainable development goals. Nat. Sustain. 2, 805-814 (2019).

30. Chaffin, B. C. et al. Transformative environmental governance. Annu. Rev. Environ. Resour. 41, 399-423 (2016).

31. Ostrom, E. Beyond markets and states: polycentric governance of complex economic systems. Am. Economic Rev. 100, 641-672 (2010). Polycentric governance can incorporate actors across levels with different dynamics thereby facilitating learning and innovation.

32. Najam, A. The case against a new international environmental organization. Glob. Gov.: A Rev. Multilateralism Int. Organ. 9, 367-384 (2003).

33. Swilling, M. The Age of Sustainability: Just Transitions in a Complex World. (Routledge, 2019).

34. Folke, C., et al. Resilience thinking: integrating resilience, adaptability and transformability. Ecol. Soc. 15, 20 (2010).

35. Benson, M. H. \& Craig, R. K. The End of Sustainability: Resilience and the Future of Environmental Governance in the Anthropocene. (University Press of Kansas, 2017).

36. Brand, U. "Transformation" as a new critical orthodoxy: The strategic use of the term "Transformation" does not prevent multiple crises. GAIA-Ecol. Perspect. Sci. Soc. 25, 23-27 (2016).

37. Geels, F. W. The multi-level perspective on sustainability transitions: Responses to seven criticisms. Environ. Innov. Soc. Transit. 1, 24-40 (2011). Article discusses the multilevel perspective framework for analysing sustainability transitions, which emerge from a specific constellation of conditions that interact in complex ways.

38. Grin, J., Rotmans, J., Schot, J. Transitions to Sustainable Development: New Directions in the Study of Long Term Transformative Change (Routledge, 2010).

39. Rotmans, J. \& Loorbach, D. Complexity and transition management. J. Ind. Ecol. 13, 184-196 (2009).

40. Gunderson, L. H., \& Holling, C. S. Panarchy: Understanding Transformations in Human and Natural Systems (Island Press, 2002).

41. Ostrom, E. Reformulating the commons. Swiss Political Sci. Rev. 6, 29-52 (2000).

42. Bollier, D. The Commons, Short and Sweet. Bollier http://www.bollier.org/ commons-short-and-sweet (2011).

43. Bauwens, M., Kostakis, V., Pazaitis, A. Peer to Peer: The Commons Manifestor. (University of Westminster Press, 2019). 
44. Chapin, F. S. et al. Ecosystem stewardship: sustainability strategies for a rapidly changing planet. Trends Ecol. Evol. 25, 241-249 (2010). Specific strategies for active ecosystem stewardship can boost adaptive capacity and resilience of social-ecological systems.

45. Dasgupta P., et al. Economic Growth, Human Development, and Welfare. in Rethinking Society for the 21st Century: Report of the International Panel on Social Progress (Cambridge University Press, 2018).

46. Coenen, L., Benneworth, P. \& Truffer, B. Toward a spatial perspective on sustainability transitions. Res. Policy 41, 968-979 (2012).

47. Geels, F. W. Regime resistance against low-carbon transitions: introducing politics and power into the multi-level perspective. Theory, Cult. Soc. 31, 21-40 (2014)

48. Milly, P. C. et al. Stationarity is dead: whither water management? Science 319, 573-574 (2008).

49. Craig, R. K. Stationarity is dead-long live transformation: five principles for climate change adaptation law. Harv. Environ. L Rev. 34, 9 (2010).

50. Bennett, E. M. et al. Bright spots: seeds of a good Anthropocene. Front. Ecol. Environ. 14, 441-448 (2016).

51. Kroeker, K. J. et al. Impacts of ocean acidification on marine organisms: quantifying sensitivities and interaction with warming. Glob. Change Biol. 19, 1884-1896 (2013).

52. OECD. Environmental and Climate Change: Issues in the Shipbuilding Industry (OECD, 2010).

53. NGO Shipbreaking Platform. Impact Report 2018-2019 (2019).

54. IMO. Guidelines on Ship Recycling. RES A. 962 (IMO, 2005).

55. IMO. Hong Kong Convention for the Safe and Environmentally Sound Recycling of Ships, 2009 (Not yet in force) (IMO, 2009).

56. EU Parliament. EU Regulation on Ship Recycling and Amending Reg No. 1013/ 2006 and Directive 2009/16/EC. Reg No. 1257/2013. (European Parliament, 2013).

57. IMO. Strategy on Reduction of GHG Emissions from Ships. RES MEPC.304 (72) (IMO, 2018).

58. Costello, C., Cao, L., Gelcich, S. The Future of Food from the Sea (World Resources Institute, 2019).

59. Christian, C. et al. A review of formal objections to Marine Stewardship Council fisheries certifications. Biol. Conserv. 161, 10-17 (2013).

60. Chase, C. Human Rights Groups Criticize MSC's New Chain of Custody Standard. SeafoodSource https://www.seafoodsource.com/human-rightsgroups-criticize-msc-s-new-chain-of-custody-certification (2019).

61. UN. Revised draft text of an agreement under the United Nations Convention on the Law of the Sea on the conservation and sustainable use of marine biological diversity of areas beyond national jurisdiction (Advance, Unedited Version) (United Nations, 2019).

62. Smith, A., Stirling, A. \& Berkhout, F. The governance of sustainable sociotechnical transitions. Res. Policy 34, 1491-1510 (2005).

63. Bennett, N. J. et al. Environmental Stewardship: A Conceptual Review and Analytical Framework. Environ. Manag. 61, 597 (2018). Article proposes an analytical framework to understand factors that lead to the success or failure of environmental stewardship in different contexts and how to support local efforts.

64. Armitage, D., Mbatha, P., Muhl, E. K., Rice, W. \& Sowman, M. Governance principles for community-centered conservation in the post-2020 global biodiversity framework. Conserv. Sci. Pract. 2, e160 (2020).

65. Unger, R. M. Democracy Realized: The Progressive Alternative. (Verso, 1998).

66. Lubchenco, J., Cerny-Chipman, E. B., Reimer, J. N. \& Levin, S. A. The right incentives enable ocean sustainability successes and provide hope for the future. Proc. Natl Acad. Sci. USA 113, 14507-14514 (2016). Incentives through economic or social norms can demonstrably improve management and policy for more sustainable ocean activities.

67. Bollier, D. New Forms of Network-based Governance. P2P Foundation http:// www.bollier.org/blog/new-forms-network-based-governance 2016).

68. Chaffin, B. C., Gosnell, H. \& Cosens, B. A. A decade of adaptive governance scholarship: synthesis and future directions. Ecol. Soc. 19, 56 (2014).

69. Jessop, B. Metagovernance. in Sage Handbook of Governance (ed. Bevir, M.) 106-123 (Sage, 2011).

70. UN Secretary-General. Critical Milestones towards Coherent, Efficient and Inclusive Follow-Up and Review at the Global Level. U.N. Doc. A/70/684 annex 25-27 (United Nations, 2016).

71. The Antarctic Treaty 402 U.N.T.S. 71 (1961).

72. Westley, F. R. et al. A theory of transformative agency in linked socialecological systems. Ecol. Soc. 18, 27 (2013). Article proposes a theory of strategic agency, which links particular strategies, on the part of transformative agents, to phases of system changes.

73. Haberl, H., Fischer-Kowalski, M., Krausmann, F., Martinez-Alier, J. \& Winiwarter, V. A socio-metabolic transition towards sustainability? Challenges for another Great Transformation. Sustain. Dev. 19, 1-14 (2011).

74. Österblom, H. \& Folke, C. Emergence of global adaptive governance for stewardship of regional marine resources. Ecol. Soc. 18, 4 (2013).
75. Dorsch, M. J. \& Flachsland, C. A polycentric approach to global climate governance. Glob. Environ. Politics 17, 45-64 (2017).

76. Jordan, A., Huitema, D., Van Asselt, H., Forster, J. Governing climate change: Polycentricity in action? (Cambridge University Press, 2018).

77. Sands, P., Peel, J., Fabra, A., Mackenzie, R. Principles of International Environmental Law, 4th edn. (Cambridge University Press, 2018).

78. Pahl-Wostl, C. Governance of the water-energy-food security nexus: a multilevel coordination challenge. Environ. Sci. Policy. 92, 356-367 (2017).

79. Aligica, P. D. Tarko, V. Polycentricity: from Polanyi to Ostrom, and beyond. Governance 25, 237-262 (2012).

80. Cole, D. H. Advantages of a polycentric approach to climate change policy. Nat. Clim. Change 5, 114-118 (2015).

81. Dietz, T., Ostrom, E. \& Stern, P. C. The struggle to govern the commons. Science 302, 1907-1912 (2003).

82. Blythe, J. et al. The dark side of transformation: latent risks in contemporary sustainability discourse. Antipode 0, 1-18 (2018).

83. Mbatha, N. P. The influence of plural governance systems on rural coastal livelihoods: The case of Kosi Bay. (University of Cape Town, 2018).

84. Neumann, B. \& Unger, S. From voluntary commitments to ocean sustainability. Science 363, 35-36 (2019).

85. Pickering, J., McGee, J. S., Stephens, T. \& Karlsson-Vinkhuyzen, S. I. The impact of the US retreat from the Paris Agreement: Kyoto revisited? Clim. policy 18, 818-827 (2018).

86. Grorud-Colvert, K. et al. High-profile international commitments for ocean protection: Empty promises or meaningful progress? Mar. Policy 105, 52-66 (2019).

87. African Model Law for the Protection of the Rights of Local Communities, Farmers and Breeders, and for the Regulation of Access to Biological Resources (Organisation of African Unity, 2000).

88. Convention on Biological Diversity 1760 U.N.T.S.69 (United Nations, 1992).

89. Nagoya Protocol on Access to Genetic Resources and the Fair and Equitable Sharing of Benefits Arising from their Utilization to Convention on Biological Diversity, United Nations. UNEP/CBD/COP/DEC/X/1 (United Nations, 2014).

90. Harrison,J. Step-wise guide for the implementation of international legal and policy instruments related to deep-sea fisheries and biodiversity conservation in areas beyond national jurisdiction (FAO, 2019).

91. FAO. Voluntary Guidelines for Securing Sustainable Small-Scale Fisheries in the Context of Food Security and Poverty (FAO, 2015).

92. Bridgewater, $\mathrm{P}$. The Man and Biosphere programme of UNESCO: rambunctious child of the sixties, but was the promise fulfilled? Curr. Opin. Environ. Sustain. 19, 1-6 (2016).

93. Penjueli, M. SDG Ocean Governance for Sustainability. In Spotlight on Sustainable Development: Reshaping Governance for Sustainability Global Civil Society Report on the 2030 Agenda and the SDGs (Spotlight 2030, 2019).

94. Boyle, A. Human rights and the environment: where next? Eur. J. Int. Law 23 613-642 (2012).

95. UN General Assembly. United Nations Conference on the Human Environment. A/RES/2994 (1972)

96. UN Commission on Human Rights. Human Rights and the Environment. E/ CN.4/RES/1994/65 (1994)

97. UN Commission on Human Rights. Human Rights and the Environment. E/ CN.4/RES/1995/14 (1995).

98. UN Commission on Human Rights. Human Rights and the Enviroment. E/ CN.4/RES/1996/13 (1996).

99. UN General Assembly. Towards a Global Pact for the Environment A/RES/72/ 277 (2019).

100. IUCN Environmental Law Programme. Draft International Covenant on Environment and Development - Implementing Sustainability. 5th edn (Gland, 2015).

101. UN Environmental Programme. Environmental Rule of Law: First Global Report (UNEP, 2019).

102. Seufert, P. The FAO voluntary guidelines on the responsible governance of tenure of land, fisheries and forests. Globalizations 10, 181-186 (2013).

103. Weston, B. H. \& Bollier, D. Regenerating the human right to a clean and healthy environment in the commons renaissance. Copyright by Burns $\mathrm{H}$. Weston and David Bollier (2011).

104. Orellana, M. The Case for a Right to a Healthy Environment. Human Rights Watch https://www.hrw.org/news/2018/03/01/case-right-healthyenvironment (2018).

105. Boyd, D. Statement of the UN Special Rapporteur for Human Rights and the Environment at the 73rd Session of the General Assembly. UN Human Rights Office of the High Commissioner (2018).

106. UN Global Compact Ocean Stewardship 2030: Ten ambitions and recommendations for growing sustainable ocean business. (ed. Pretlove, B.). (United Nations Global Compact, 2020). Ocean stewardship by businesses includes processes for sustainable seafood, decarbonized shipping, sustainable 
ocean electricity, removing nutrient and plastic waste stream, and mapping the ocean.

107. Leape, J., et al. Technology, Data and New Models for Sustainably Managing Ocean Resources (World Resources Institute, 2020)

108. TWI2050. The digital revolution and sustainable development opportunities and challenges. in The World in 2050 (International Institute of Applied Systems Analysis, 2019).

109. Domingos, P. The Master Algorithm: How the quest for the ultimate learning machine will remake our world (Basic Books, 2015)

110. Tegmark, M. Life 3.0: Being Human in the Age of Artificial Intelligence. (Knopf, 2017).

111. Craglia, M., et al. Artificial Intelligence: A European Perspective. https://doi. org/10.2760/936974,JRC113826 (Publications Office of the EU, 2018).

112. Young, O. R. et al. Moving beyond panaceas in fisheries governance. Proc. Natl Acad. Sci. USA 115, 9065-9073 (2018).

113. Bollier, D. \& Weston, B. H. Reimagining ecological governance through human rights and a rediscovery of the Commons. in Thought, Law, Rights and Action in the Age of Environmental Crisis. (Edward Elgar Publishing, 2015).

114. Vidas, D. The Anthropocene and the international law of the sea. Philos. Trans. R. Soc. A 369, 909-925 (2011).

115. Köhler, J. et al. An agenda for sustainability transitions research: State of the art and future directions. Environ. Innov. Soc. Transit. 31, 1-32 (2019).

116. Narberhaus, M., \& Sheppard, A. Re-imagining activism: a practical guide for the greater transition (Smart CSOs LAb, 2015).

117. Kelly, M. Owning Our Future The Emerging Ownership Revolution. (BerretKoehler, 2012).

118. Swilling, M., et al. The Ocean Transition: What to Learn from System Transitions (World Resources Institute, 2020).

119. Ruckelshaus, M., Klinger, T., Knowlton, N. \& DeMaster, D. P. Marine ecosystem-based management in practice: scientific and governance challenges. BioScience 58, 53-63 (2008).

120. EU Parliament. Establishing a Framework for Maritime Spatial Planning. Directive 2014/89/EU (2014).

121. de Grunt, L. S., Ng, K. \& Calado, H. Towards sustainable implementation of maritime spatial planning in Europe: a peek into the potential of the Region Sea Conventions playing a stronger role. Mar. Policy 95, 102-110 (2018).

122. UN Office for Disaster Risk Reduction Global Assessment Report on Disaster Risk Reduction (UNDRR, 2019).

123. Hoshino, E., van Putten, I., Pascoe, S. \& Vieira, S. Individual transferable quotas in achieving multiple objectives of fisheries management. Mar. Policy 113, 103744 (2019)

124. Melnychuk, M. C. et al. Which design elements of individual quota fisheries help to achieve management objectives? Fish. Fish. 17, 126-142 (2016).

125. Chambers, C. \& Carothers, C. Thirty years after privatization: A survey of Icelandic small-boat fishermen. Mar. Policy 80, 69-80 (2017).

126. Edvardsson, K. N., Păstrăv, C. \& Benediktsson, K. Mapping the geographical consolidation of fishing activities in Iceland during the maturation of the ITQ fisheries management system. Appl. Geogr. 97, 85-97 (2018).

127. Lyons, C., Carothers, C. \& Coleman, J. Alaska's community development quota program: A complex institution affecting rural communities in disparate ways. Mar. Policy 108, 103560 (2019).

128. Kittinger, J. N. et al. Committing to socially responsible seafood. Science 356, 912-913 (2017).

129. Kroodsma, D. A. et al. Tracking the global footprint of fisheries. Science 359, 904-908 (2018).

130. Geels, F. W., Sovacool, B. K., Schwanen, T. \& Sorrell, S. Sociotechnical transitions for deep decarbonization. Science 357, 1242-1244 (2017).

131. Sharp, R., et al. InVEST 3.7.0. User's Guide. (The Natural Capital Project, Stanford University, University of Minnesota, The Nature Conservancy, and World Wildlife Fund, 2018).

132. Arkema, K. K., et al. Integrating fisheries management into sustainable development planning. Ecol. Soc. 24, 1 (2019).

133. Arkema, K. K. et al. Embedding ecosystem services in coastal planning leads to better outcomes for people and nature. Proc. Natl Acad. Sci. USA 112, 7390-7395 (2015). A science-policy process with the government of Belize leads to an integrated coastal management plan that improves value from lobster fisheries, tourism, and avoided damages from hurricanes and sea level rise.

134. Silver J., et al. Advancing coastal risk reduction science and implementation by accounting for climate, ecosystems and people. Front. Marine Sci. https://doi. org/10.3389/fmars.2019.00556 (2019).

135. Karkkainen, B. C. New governance in legal thought and in the world: some splitting as antidote to overzealous lumping. Minn. Law Rev. 89, 471 (2001).

136. Garmestani, A. S. et al. Untapped capacity for resilience in environmental law. Proc. Natl Acad. Sci. USA 116, 19899-19904 (2019).

137. Urgenda Foundation v. The Netherlands [2015] HAZA C/09/00456689

138. La Rose v Her Majesty the Queen. T-1750-19 (Federal Court of Canada, 2019).
139. W. W. F. (World Wildlife Fund) South Africa v Minister of Agriculture, Forestry and Fisheries and others. 4 All SA 889 (WCC, 2018).

140. Ruling Ecuadorian Sala Penal de la Corte Provincial. Protection Action. Ruling No. 11121-2011-0010. Casillero NO. 826 (2011).

141. Ruling Colombia Constitutional Court. T-622. Expediente T-5.016.242 (2016).

142. Mohammed, S. Salim v. State of Uttarakhand, Writ Petition (PIL) No. 126 of 2014 (High Court of Uttarakhand, 2017).

143. Convention on Access to Information, Public Participation In Decision-Making and Access to Justice in Environmental Matters, Vol. 38 (ILM, 1999).

144. Harris, P. Ocean Governance Amidst Climate Change. in Climate Change and Ocean Governance. (eds McGregor, I., Yerbury, H.) (Cambridge University Press, 2019).

145. Jentoft, S. The Small-scale Fisheries Guidelines: Global Implementation. (Springer, 2017)

146. Weitz, N., Carlsen, H., Nilsson, M. \& Skånberg, K. Towards systemic and contextual priority setting for implementing the 2030 Agenda. Sustain. Sci. 13, 531-548 (2018).

147. Coastal Zone Management Authority and Institute (CZMAI). Belize Integrated Coastal Zone Management Plan. (CZMAI, Belize City, 2016).

148. Arkema, K. K. \& Ruckelshaus, M. Transdisciplinary research for conservation and sustainable development planning in the Caribbean. in Conservation for the Anthropocene Ocean (eds Levin, P. S. \& Poe, M.), 333-358 (Elsevier Press, 2017).

149. Douvere, F. Danger Listed site Belize Barrier Reef gets visionary integrated management plan. (UNESCO, 2016) http://whc.unesco.org/en/news/1455? utm_source $=$ April $+2016+$ Newsletter\&utm_campaign $=$ NatCap + Newsletter\&utm_medium $=$ email.

150. Gelcich, S. et al. Navigating transformations in governance of Chilean marine coastal resources. Proc. Natl Acad. Sci. USA 107, 16794-16799 (2010).

151. Gelcich, S. et al. Fishers' perceptions on the Chilean coastal TURF system after two decades: problems, benefits, and emerging needs. Bull. Mar. Sci. 93, 53-67 (2017).

152. Marín, A., Gelcich, S., Castilla, J. C. \& Berkes, F. Exploring social capital in Chile's coastal benthic comanagement system using a network approach. Ecol. Soc. 17, 13 (2012).

153. Gelcich, S., Reyes-Mendy, F. \& Rios, M. A. Early assessments of marine governance transformations: insights and recommendations for implementing new fisheries management regimes. Ecol. Soc. 24, 12 (2019).

154. Österblom, H., Jouffray, J.-B., Folke, C. \& Rockstrom, J. Emergence of a global science-business initiative for ocean stewardship. Proc. Natl Acad. Sci. USA 114, 9038-9043 (2017). A new stewardship partnership by the world's leading seafood industry corporations links science and business, and wildcapture fisheries and aquaculture, increasing the chances for sustainable seafood production.

\section{Acknowledgements}

HÖ was funded by the Walton Family Foundation (grant 2018-1371), the David and Lucile Packard Foundation (grant 2019-68336), and the Gordon and Betty Moore Foundation (grant GBMF5668.02). MR was supported by gifts from Peter and Helen Bing and Roger and Vicki Sant. This research is adapted from a Blue Paper commissioned by the High Level Panel for a Sustainable Ocean Economy entitled "The ocean transition: What to learn from system transitions" [https://www.oceanpanel.org/bluepapers/ocean-transition-what-learn-system-transitions].

\section{Author contributions}

T.B.R., M.R. and M.S. conceived of the topics and wrote the manuscript. E.A., H.Ö., S.G. and P.M. conceived of the topics, provided content for several Boxes, and helped edit the paper.

\section{Competing interests}

H.Ö. is leading the scientific efforts associated to the SeaBOS initiative (with funding that is independent from the companies of the initiative).

\section{Additional information}

Correspondence and requests for materials should be addressed to M.R.

Peer review information Nature Communications thanks Louis Celliers and the other, anonymous, reviewers for their contribution to the peer review of this work.

Reprints and permission information is available at http://www.nature.com/reprints

Publisher's note Springer Nature remains neutral with regard to jurisdictional claims in published maps and institutional affiliations. 
(c) (i) Open Access This article is licensed under a Creative Commons Attribution 4.0 International License, which permits use, sharing, adaptation, distribution and reproduction in any medium or format, as long as you give appropriate credit to the original author(s) and the source, provide a link to the Creative Commons license, and indicate if changes were made. The images or other third party material in this article are included in the article's Creative Commons license, unless indicated otherwise in a credit line to the material. If material is not included in the article's Creative Commons license and your intended use is not permitted by statutory regulation or exceeds the permitted use, you will need to obtain permission directly from the copyright holder. To view a copy of this license, visit http://creativecommons.org/ licenses/by/4.0/.

(C) The Author(s) 2020 